\title{
Renewable Energy Technologies for Energy Efficient Buildings: The Case of Kuwait
}

\author{
Bader Alshuraiaan
}

check for updates

Citation: Alshuraiaan, B. Renewable Energy Technologies for Energy Efficient Buildings: The Case of Kuwait. Energies 2021, 14, 4440. https://doi.org/10.3390/en14154440

Academic Editors: Sergio

Gómez Melgar and José Manuel Andújar Márquez

Received: 26 May 2021

Accepted: 19 July 2021

Published: 23 July 2021

Publisher's Note: MDPI stays neutral with regard to jurisdictional claims in published maps and institutional affiliations.

Copyright: (C) 2021 by the author. Licensee MDPI, Basel, Switzerland. This article is an open access article distributed under the terms and conditions of the Creative Commons Attribution (CC BY) license (https:/ / creativecommons.org/licenses/by/ $4.0 /)$.
Department of Mechanical Engineering, Kuwait University, Safat 13060, Kuwait; alshuraiaan@yahoo.com

\begin{abstract}
The purpose of this study is to identify the most relevant renewable energy technologies for buildings and to assess the effectiveness of their implementation in the long term for Kuwait. Methods of analogies and comparisons were used to determine the features of energy efficiency based on the technologies under study. The study proposes the methodological approach to assessing the effectiveness of the introduction of renewable energy technologies, determining the direction of increasing the energy efficiency of buildings and the investment efficiency of introducing these technologies. Renewable energy efficiency analysis for buildings in Kuwait confirms that solar energy systems have been the most widely available for widespread use of solar energy over the past three years. An increasing level of energy efficiency with a decrease in the notional cost of increasing energy savings is characteristic of solar collectors with booster reflectors. The proposed model for assessing the level of energy saving provides an opportunity for economic justification of introducing renewable energy technology in buildings.
\end{abstract}

Keywords: energy efficiency; energy saving; investments; net present value; payback period; sustainable development

\section{Introduction}

Climate warming is the main threat to all countries in the world. The Risk Report of the World Economic Forum, which took place in January 2019 in Davos, emphasized five risks related to climate change out of ten possible risks for the future development of world civilization. Humanity has only 12 years to eliminate them. This requires coordinated action on this issue by all countries of the world, without exception. First of all, it is necessary to maintain the level of climate warming within 1.5 degrees (according to the terms of the Paris Climate Agreement), which has not yet been achieved. According to the forecasts of the World Bank experts, by 2050, 140 million of the world's inhabitants may become internally displaced due to climate change [1].

Renewable energy targets are on the rise in many countries. For example, the European Union has changed the minimum target until 2030 from $27 \%$ to $32 \%$ [2]. It is planned to increase the share of renewables in total US energy demand from $11 \%$ to $17 \%$ [3]. At the same time, the Hawaiian Islands in the United States intend to secure $70 \%$ of their energy independence by 2030 , with $40 \%$ of which coming from renewable energy sources [4]. China, a world leader in energy production and consumption, uses renewable energy sources to meet growing energy demand and prevent air pollution. In 2018, China accounted for more than half of all global $94 \mathrm{GW}$ solar photovoltaic (PV) systems. However, in 2018, a quota was introduced for the use of solar PV installations and it was decided to phase out tariffs for their commissioning, which is expected to lead to a decrease in installed capacity [5]. The Russian Federation, which has one of the world's largest fossil fuel resources, is stepping up the use of solar and wind energy by organizing auctions to boost employment, support science and technology, and improve energy efficiency for people living in isolated areas [6]. Kuwait has decided to diversify its sources of electricity. For instance, there have been multiple projects launched to meet the $15 \%$ 
of Kuwait's electricity demand from renewables by 2030. The Renewable Energy Park (Al-Shagaya Renewable Energy Park-SREP), which is one of those projects, provides PV, CSP (Concentrated Solar Power), and wind power solutions. Although it has been designed in several phases, much remains to be done to achieve the goal of reducing "carbon dioxide emissions". Kuwait's emissions per capita are expected to be more than four times the global average in 2035. This problem encourages Kuwaiti leaders to take immediate actions [7].

At the same time, an increase in living standards in the future is inextricably linked with an increase in the unit consumption of energy and energy carriers per inhabitant. A large part of these costs is related to providing a comfortable environment for a person to live or stay in a particular building. Maintaining a comfortable environment through improved energy efficiency in buildings is important not only to keep people safe and productive, but also to reduce carbon emissions by using renewable energy sources instead of fossil and carbonized ones. Optimal environmental parameters for health and performance are provided not only through the use of heating, ventilation, and air conditioning (HVAC) or thermal systems, but also through constructive energy-efficient solutions implemented in the architecture of buildings. However, the development of modern architecture, the expansion of the typology of residential and public buildings pose problems that cannot be solved based on traditional experience. The limited nature of natural resources forces humankind to resort to a policy of saving them, in particular, energy saving in architecture and construction in general. Calculation and regulation of the impact on the microclimate and the energy balance of premises are among the priority tasks of the construction of an energy-efficient building. In the context of globalization, improving the energy efficiency of buildings has become one of the most important aspects of government regulation. In addition to saving energy, these requirements are aimed at protecting the environment from harmful emissions and rational use of natural resources. At the same time, the solution to the problem of reducing energy consumption is largely implemented by the introduction of energy efficient technologies, modernization of energy supply systems, and the use of renewable energy sources in buildings.

Parameters of buildings, forming their energy efficiency based on renewable energy technologies should be laid at the pre-investment and investment stages of construction. In doing so, energy efficiency can be considered both in terms of economic benefits and in terms of achieving sustainability goals by reducing carbon emissions through the use of renewable energy sources instead of primary energy sources. With this approach to the definition of energy efficiency, it becomes necessary to develop scientific foundations, methods and means for increasing the energy efficiency of buildings. This served as the motivation for this study, which is aimed at developing a methodological approach based on a model for assessing the effectiveness of the introduction of renewable energy technologies in the pre-investment phase in buildings in Kuwait.

\section{Literature Review}

Current studies and forecasts focus on possible future scenarios, according to which the total primary energy consumption and carbon dioxide emissions from energy consumption will increase [8]. Energy consumption in buildings will play a key role in this. As part of the solution to this problem, many governments and international organizations, mainly located in the US and the EU, have developed a variety of special regulations, the purpose of which is to reduce the level of energy consumption of buildings and reduce their environmental impact. This will improve the energy efficiency of buildings and promote solutions that involve the widespread use of renewable energy sources. Thus, the ZEB (Zero-Energy Building) has established itself as a benchmark for targeted achievements [9]. The University of Southampton (UK), based on the results of research on climate change, has created a simulator of fluctuations in meteorological parameters for the period up to 2080. It makes it possible to simulate changes in meteorological parameters to make climate forecasts. In the future, such predictive data can be implemented to calculate the 
energy efficiency of various buildings and optimize the design to achieve better control of energy consumption, including the use of renewable energy technologies [10,11]. Thus, the installed systems will be used longer, resulting in higher maintenance and repair costs. Solar energy systems can be used for sustainability in innovative buildings in the context of improving their performance to provide energy savings. Since the buildings sector is known to account for about $35 \%$ of final energy consumption and $40 \%$ of gas emissions, it is estimated that energy savings could be $60 \%$ if solar energy systems are used for heating and cooling [12].

There are also a number of strategies, approved in different countries, that promote the refurbishment of buildings, stimulate the dissemination of modern technologies for increasing energy efficiency, and allow reducing their impact on the environment, economic and social indicators. In addition to this, a European Commission directive has been enacted on the commitment to energy efficiency in newly constructed buildings [13]. The "Passive House" is widespread in European countries for certifying standardized buildings with low energy intensity [14]. European and American urban development and energy efficiency programs focus on ZEB. Other countries such as China, India, and Latin American countries, which are some of the main consumers of energy, are still not showing results despite significant initiatives being taken [15-17]. As part of promoting sustainable development and accelerating the transition to green building, the South African government has established an Energy Performance Certificate (EPC) for buildings. In this model, the planned optimal options for the conversion of the entire building are established on an ongoing basis, with the simultaneous use of both the shell components and the interior. Long-term investments within the framework of the model are distributed to annual short-term investments, which become more attractive to investors. To compensate for the long-term return on investment, a country's current tax incentive program is taken into account [18]. By 2025, the energy goals set by the Korea Building Energy Code are to be achieved through passive building technologies as well as zero- or near-zero-energy buildings (nZEBs) [19].

Kuwait has one of the highest per capita energy consumption rates in the world. In Kuwait, ventilation, air conditioning, and lighting systems consume about $85 \%$ of the energy used in buildings during summer peaks and $60 \%$ of the total annual energy consumption in the construction sector. Such large-scale consumption negatively affects natural resources and the environment [20]. Accordingly, the need to improve energy efficiency, to minimize the environmental footprint, and to reduce the energy use in Kuwait's construction sector is of paramount importance [21]. Kuwait, like all oil-producing countries today, is faced with a changing energy world. The shift in trends in demand, supply, and technology has led to the emergence of an energy world in which volatility in oil prices and uncertainty in the market are the defining characteristics [22]. Therefore, to ensure economic development and social prosperity in the coming years, Kuwait will need a new energy strategy, coupled with a plan to diversify the economy and reduce dependence on fossil fuels [23].

For Kuwait, by 2035, the total primary energy demand is projected to increase to 47 million TOE, which is an average of $1.5 \%$ per year. However, the achieved growth rates are significantly lower than the average annual rates of the previous five years, and this is the result of changes in population and GDP growth rates [24]. According to the forecast of the Ministry of Electricity and Water Resources, by 2030, the highest demand is expected to be reached in the amount of 30 thousand MW, while $70 \%$ of this volume will come from new housing construction [25]. This requires significant actions to be taken to employ the Energy Conservation Code and thus to improve the energy efficiency of the Kuwaiti construction sector until 2035 [26]. Today, air conditioning accounts for over $70 \%$ of the annual peak electricity demand during the summer months. However, over the forecast period, electricity demand growth is projected to slow down, increasing by an average of $1.6 \%$ per annum, reflecting the expected slowdown in economic and demographic growth and stronger adherence to energy efficiency standards in buildings [27]. The final 
electricity demand in 2035 is expected to be 60.8 TWh and the final electricity consumption to 11.9 MWh [24].

In Kuwait, as elsewhere in the world, energy conservation through improving energy efficiency in the construction sector has become of great importance. Among the main directions of energy saving in buildings, it is necessary to highlight, first of all, the construction of passive buildings with almost zero energy consumption. The use of energyefficient materials in their construction plays a special role. It is very important to introduce energy-saving equipment in order to reduce energy consumption during operation. Of great importance is the use of renewable energy technologies for a wide range of applications [28]. In accordance with international norms and standards that are being actively implemented, buildings are considered as complex energy systems in combination with enclosing structures, sources of the internal and external environment. The complex of indicators of thermal energy efficiency of a building includes an assessment of energy consumption. The assessment of the efficient use of energy for heating and/or cooling is determined based on the energy requirement of a building [29]. Geometric solutions and orientation have a significant impact on a building's energy efficiency. This is determined by building area and functional purpose of premises, facade area, size, number, type, and orientation of windows and doors, as well as width, length, compactness, configuration, shape of the building plan and premises, solutions and orientation of the quarter, streets, buildings, apartments, and premises [30].

Studies on the development of a scenario for a potential sustainable energy development are present and the issue of integrating this strategy into the framework of the Action Program for the period up to 15-20 years is being considered. The strategy is based on diversifying supply to meet $15 \%$ of demand for renewable energy sources by 2030 , reducing electricity consumption in buildings by $12 \%$ and reducing carbon dioxide emissions by $33 \%$ by 2035 [31]. In this regard, it is important to study the impact of driving forces on the energy consumption of buildings in Kuwait. Using baseline final consumption information to determine the load on residential premises provides an important foundation for understanding consumption patterns [32].

In order to assess the potential for energy savings through various criteria, one may analyze various alternatives and diagnose their implementation costs. A variety of scenarios help design the energy policy such that it permits the promotion of renewable energy in urban areas. Hence, the results of those scenarios should be clearly communicated to decision makers [33].

Today, there is a wide range of studies on renewable technology development in Kuwait. However, the problem of adapting and applying modern approaches of the world practice of using renewable energy technologies in buildings to the conditions of Kuwait remains unresolved, as well as assessing the effectiveness of their implementation. The transition to this type of building can significantly reduce the consumption of fuel and energy resources, reduce energy costs, and reduce greenhouse gas emissions. All the said has determined the purpose of this study, which is to identify the most relevant renewable energy technologies in buildings and assess the effectiveness of their implementation in the long term for Kuwait. In the process of achieving the formed research goal, the following hypotheses were proposed:

Hypothesis 1 (H1). The choice of renewable energy technology has a significant impact on the level of energy savings in Kuwait's buildings.

Hypothesis 2 (H2). The integrated implementation of renewable energy technology and storage systems has a significant impact on the level of energy savings in buildings in Kuwait.

To achieve this goal, the following tasks were identified and achieved: 
- a model for assessing the energy saving of buildings based on the introduction of renewable energy technologies was formed;

- the level of use of renewable energy sources in Kuwait in the context of the construction sector was explored;

- the energy efficiency of buildings was assessed in Kuwait based on renewable sources;

- renewable energy technologies implementation was analyzed on the basis of net present value (NPV), taking into account energy storage systems;

- the forecast of indicators of buildings' energy saving up to 2040 was formed on the basis of assessing the investment efficiency of renewable energy technologies use in Kuwaiti buildings;

- an analysis of variance (ANOVA) was carried out of the effectiveness of renewable energy technology implementation and storage systems.

\section{Materials and Methods}

The study used the methods of analogies and comparisons to determine the characteristics of the energy efficiency of the technologies under study in Kuwait. In general, it was conducted in five stages shown in Figure 1.

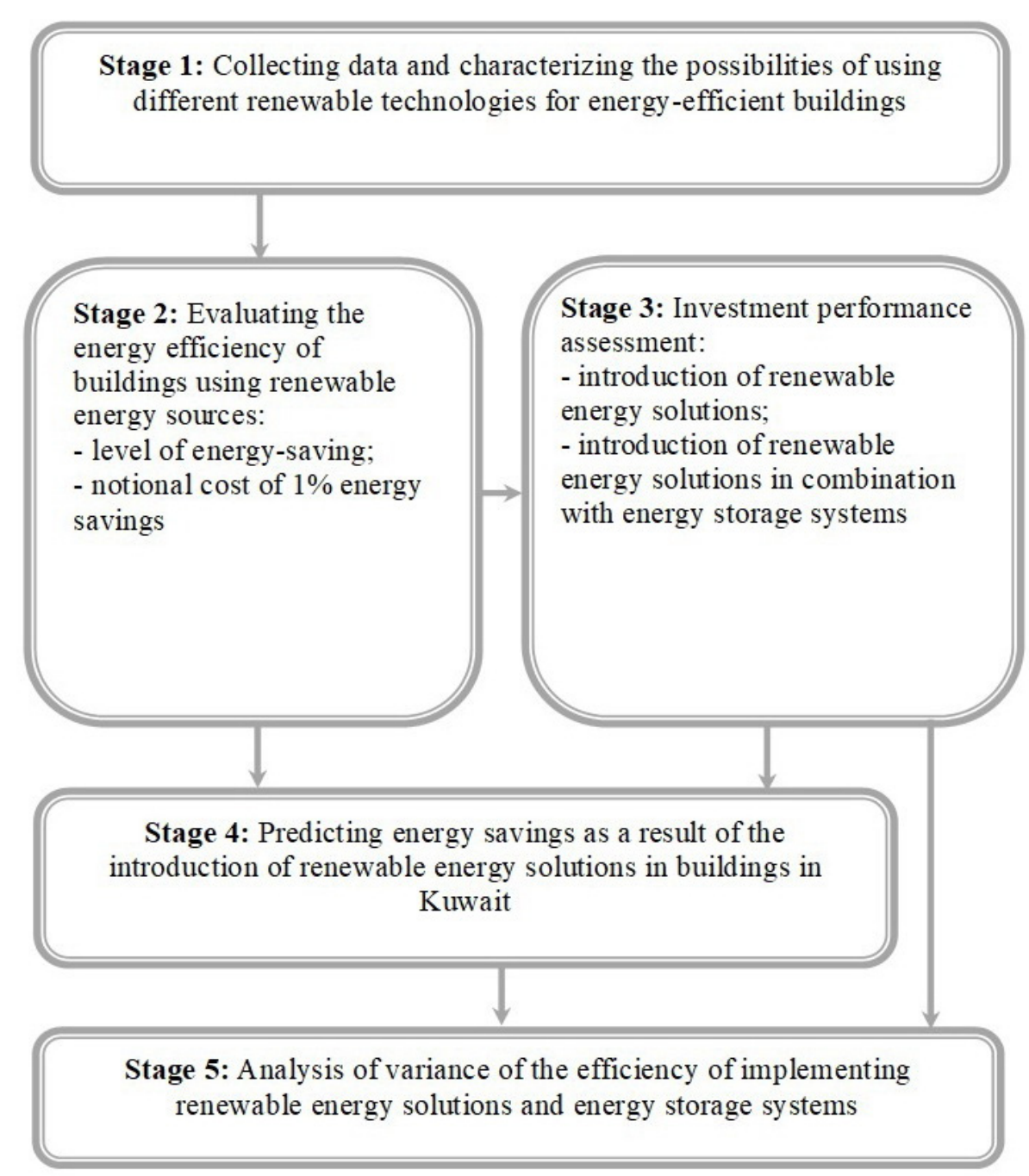

Figure 1. Research stages. Source: formed by the author.

At the first stage, information was collected, and a description of the possibilities of using different renewable technologies for energy-efficient buildings was formed. Together with this, the features of renewable energy sources use in energy-efficient buildings were 
described using such technologies as flat plate thermosiphon units, built-in collector storage, solar collectors with colored absorbers, solar collectors with booster reflectors, unglazed solar collectors (designed for hot water supply), as well as Fresnel lens for building atriums, and hybrid integrated (solar-wind) systems (used to generate power flows). Thus, various energy-using services are considered.

The second stage presupposed assessment of the energy efficiency of buildings in Kuwait using renewable energy sources by determining the level of energy savings and the notional cost of $1 \%$ of energy production. To determine the level of costs for the transition to energy-efficient buildings, a modeling method was used. Based on the formed investment projects to improve the energy efficiency of buildings, its assessment was carried out, and the average notional cost of $1 \%$ of energy efficiency for the studied renewable energy technologies was determined.

At the third stage, the investment performance of the implementation of renewable energy technology in buildings, as well as in combination with energy storage systems, was assessed on the basis of net present value. The modeling is based on the assumption that there is an efficient investment in renewable energy technologies used in building applications. Based on the econometric diagnostics of the obtained results of simulation modeling, an analysis of the interdependence of the level of energy saving and energy efficiency as a result of the introduction of a particular technology in the building, namely the corresponding volume of investments, is carried out. In this case, the following dependence is assumed:

$$
\varphi_{\tau}(\Delta E S)=e s_{0 \tau}^{i n v}+e s_{0 \tau}^{i n v} \Delta E S
$$

where $\triangle E S$ - the level of energy saving of the building as a result of the introduction of technology for the use of renewable energy sources (\%);

$\tau$-renewable energy investment option index, $\tau=\overline{1,7}$;

$\varphi_{\tau}(\Delta E S)$ - the amount of power generation for the investment option $\tau$;

$e s_{0 \tau}^{i n v}, e s_{1 \tau}^{i n v}$-parameters of the econometric model for the investment option $\tau$ on the introduction of renewable energy technology.

Based on the proposed methodological approach to the construction of investment projects for the implementation of renewable energy technologies, the mathematical expectation of the function of energy-saving volumes was determined $\varphi_{\tau}(\Delta E S)$ of a random variable $\Delta E S$ with distribution density $f(\Delta E S)$. While $f(\Delta E S)$ means:

$$
f(\Delta E S)=\frac{1}{\sigma \sqrt{2 \pi}} e^{-\frac{(\Delta E S-E R S)^{2}}{2 \sigma^{2}}}
$$

where ERS—Expected Resource Saving;

$\sigma$-the level of its possible mean deviation.

In this case, the mathematical expectation for the energy saving function (EV-Expected Value) has the following form:

$$
E V\left[\varphi_{\tau}(\Delta E S)\right]=\int_{-\infty}^{+\infty} \varphi_{\tau}(\Delta E S) f(\Delta E S) d \Delta E S
$$


Based on the substitution within the integration and replacement of certain mathematical models, the equation takes the following form:

$$
\begin{aligned}
E V\left[\varphi_{\tau}(\Delta E S)\right]= & \int_{0}^{7}\left(e s_{0 \tau}^{i n v}+e s_{1 \tau}^{i n v} \Delta E S\right) \cdot \frac{1}{\sigma \sqrt{2 \pi}} e^{-\frac{(\Delta E S-E R S)^{2}}{2 \sigma^{2}}} d \Delta E S \\
& =\frac{e s_{0 \tau}^{i n v}}{\sigma \sqrt{2 \pi}} \int_{0}^{7} e^{-\frac{(\Delta E S-E R S)^{2}}{2 \sigma^{2}}} d \Delta E S \\
& +\frac{e s_{1}^{i n v}}{\sigma \sqrt{2 \pi}} \int_{0}^{7} \Delta E S e^{-\frac{(\Delta E S-E R S)^{2}}{2 \sigma^{2}}} d \Delta E S \\
& =e s_{0 \tau}^{i n v}\left[\varphi\left(\frac{7-E R S}{\sigma}\right)+\varphi\left(\frac{E R S}{\sigma}\right)\right] \\
& +\frac{e s_{1 \tau}^{i n v}}{\sigma \sqrt{2 \pi}} \int_{0}^{7} \Delta E S e^{-\frac{(\Delta E S-E R S)^{2}}{2 \sigma^{2}}} d \Delta E S
\end{aligned}
$$

where $\varphi(y)$-integral Laplace function taking into account the parameter $\mathrm{y}$.

In order to determine the integral $\frac{1}{\sigma \sqrt{2 \pi}} \int_{0}^{7} \Delta E S e^{-\frac{(\Delta E S-E R S)^{2}}{2 \sigma^{2}}} d \Delta E S$, it is assumed that $x=\frac{\Delta E S-E R S}{\sigma}$ and $x$ is accepted as a new variable. As a result, $\triangle E S=x \sigma+E R S$. While, $d \triangle E S=\sigma d x$. By replacing the variables, one can get:

$$
\begin{gathered}
\frac{1}{\sigma \sqrt{2 \pi}} \int_{0}^{7} \Delta E S e^{-\frac{(\Delta E S-E R S)^{2}}{2 \sigma^{2}}} d \Delta E S=\frac{\sigma}{\sigma \sqrt{2 \pi}} \int_{-E R S / \sigma}^{(7-E R S) / \sigma}(\mathrm{x} \sigma+E R S) e^{\frac{x^{2}}{2}} d \mathrm{x}= \\
\frac{\sigma}{\sqrt{2 \pi}} \int_{-E R S / \sigma}^{(7-E R S) / \sigma} \mathrm{x} \sigma e^{\frac{x^{2}}{2}} d \mathrm{x}+\frac{E R S}{\sqrt{2 \pi}} \int_{-E R S S / \sigma}^{(7-E R S) / \sigma} e^{\frac{x^{2}}{2}} d \mathrm{x}= \\
\frac{\sigma}{\sqrt{2 \pi}} \int_{-\frac{(7-E R S)}{\sigma}}^{\frac{E R S}{2}} e^{\frac{x^{2}}{2}} d\left(-\frac{x^{2}}{2}\right)+E R S\left[\varphi\left(\frac{7-E R S}{\sigma}\right)+\varphi\left(\frac{E R S}{\sigma}\right)\right]=\frac{\sigma}{\sqrt{2 \pi}}\left[e^{-\frac{E R S^{2}}{2 \sigma^{2}}}-e^{-\frac{(7-E R S)^{2}}{2 \sigma^{2}}}\right]+E R S\left[\varphi\left(\frac{7-E R S}{\sigma}\right)+\varphi\left(\frac{E R S}{\sigma}\right)\right]
\end{gathered}
$$

Thus, the mathematical expectation of a building's energy saving as a result of the introduction of renewable energy technologies will have the following form:

$$
\begin{gathered}
E V_{\tau}=E V[\varphi(\Delta E S)]=e s_{0 \tau}^{i n v}\left[\varphi\left(\frac{7-E R S}{\sigma}\right)+\varphi\left(\frac{E R S}{\sigma}\right)\right]+ \\
+e s_{1 \tau}^{i n v}\left\{E R S\left[\varphi\left(\frac{7-E R S}{\sigma}\right)+\varphi\left(\frac{E R S}{\sigma}\right)\right]+\frac{\sigma}{\sqrt{2 \pi}}\left(e^{-\frac{E R S S^{2}}{2 \sigma^{2}}}-e^{-\frac{(7-E R S)^{2}}{2 \sigma^{2}}}\right)\right\}
\end{gathered}
$$

The proposed methodological approach to assessing the effectiveness of the introduction of technologies for the use of renewable energy sources allows one to take into account the drivers of energy saving, to determine the directions for improving the energy efficiency of buildings and to promote favorable investment support for the introduction of renewable energy technologies.

The fourth stage implied forecasting energy savings in buildings after introducing renewable energy solutions in Kuwait buildings. When predicting the effectiveness of investments in renewable energy technologies in buildings, it is assumed that maintenance costs can be as low as $1 \%$ per year of investments [34]. Investment performance forecasting in this study has a limitation. It lies in the fact that, in the forecasting period, the conditions of implementation and operation of the studied technologies may change, as well as new substitute technologies may emerge. All of this may affect the estimated profitability of the investments in renewable energy technologies in buildings.

Determining the economic value of introducing renewable energy technologies for buildings is based on a net present value $\left(N P V_{\text {tech }}\right)$ in the period $i$ for every renewable energy technology:

$$
N P V_{\text {tech }}=\sum_{i=1}^{n} \frac{C F_{\text {techi }}}{(1+d)^{i}}-\sum_{i=0}^{n} \frac{I n v_{\text {tech }}}{(1+d)^{i}}
$$

When justifying the economic feasibility of introducing technologies for using renewable energy sources for buildings, the possible emergence of new technologies was also taken into account. At the same time, attention was paid to the decrease in the possible level of investment in the introduction of renewable energy technologies used in building applications in the period under review as a result of their obsolescence. Taking into account that the assessment has been formed for a long-term period ( 20 years), it should be noted that there is a certain limitation of the proposed methodological approach, which manifests itself as the emergence of innovative technologies both in construction and in renewable energy. This can distort projected performance indicators in the context of economic benefits. 
The final research stage was the analysis of variance of the effectiveness of the introduction of renewable energy solutions and energy storage systems. This analysis was carried out with reference to a possible $5 \%$ deviation of indicators designating the influence of the introduction of renewable energy solutions and energy storage systems on energy saving in buildings. This allowed an inference that the above factors do not have a notable effect on the energy saving level for all technologies under study.

\section{Results}

Kuwait is entirely dependent on fossil fuel resources for energy production, and its energy demand will triple by 2030. By this time, in order to expand the range of its own energy balance, Kuwait plans to increase the share of renewable generation to fifteen percent [35]. At the same time, Kuwait is actively developing in this direction (Figure 2).

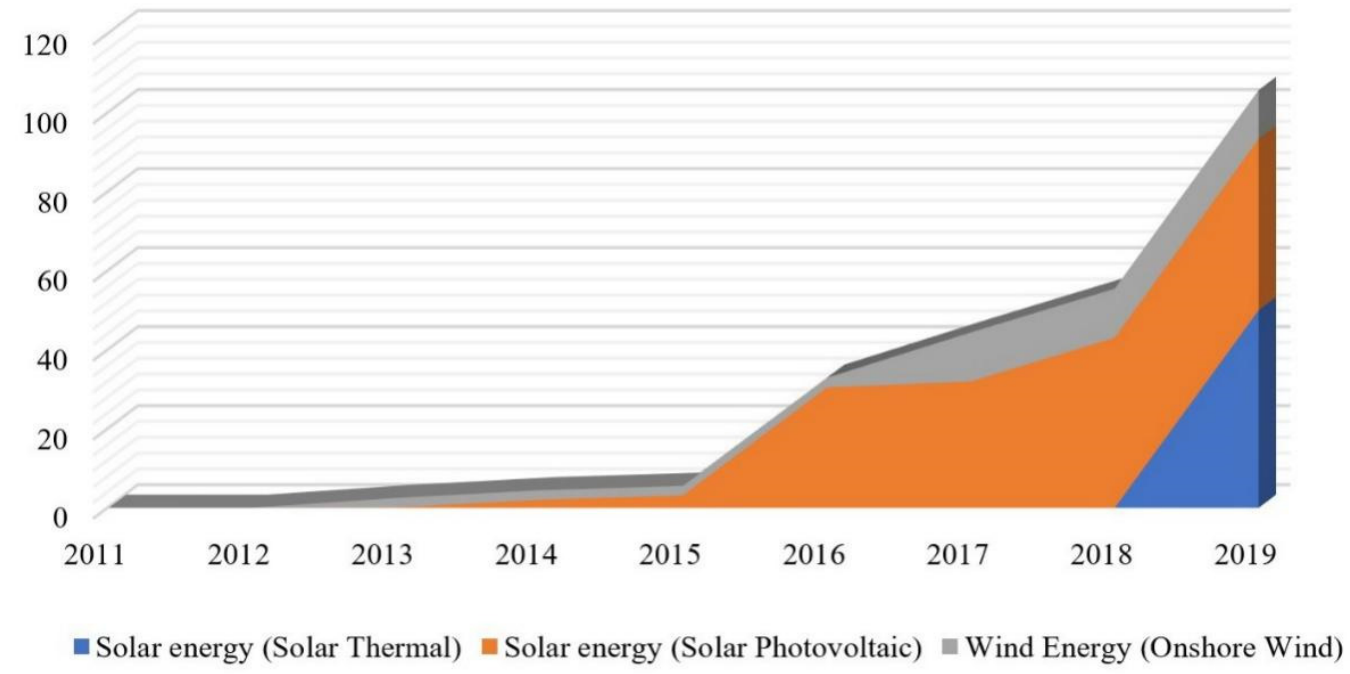

Figure 2. Renewable installed power capacity in Kuwait, MW. Source: built by the author based on the data from International Renewable Energy Agency [36].

Over the past three years, Kuwait has seen a significant increase in the use of renewable energy sources. However, improving energy efficiency in building construction in Kuwait requires clear, long-term government policies, coupled with well-thought-out comprehensive strategies, backed by adequate capacity to implement them and sufficient enforcement. The Kuwait Energy Conservation Code, adopted in 1983, lacked adequate oversight, auditing, and enforcement. For 27 years, the 1983 code has not been revised, and the construction sector is one of the main sources of inefficient energy use with a very large reserve of energy efficient buildings. Almost thirty years later, a revised draft code was adopted with stricter requirements for energy efficiency measures in new buildings. In 2014, this Energy Conservation Code was revised again to take into account even stricter standards in the context of the minimum energy efficiency requirements for the design of new buildings in Kuwait. The 2017 Code for Government and Commercial Buildings established minimum requirements for power density, material properties, and the use of efficient air conditioning systems.

Tighter adherence to regulations and codes in the buildings sector is expected to contribute to a significant slowdown in residential energy demand growth. It can also be facilitated by a slowdown in population growth and economic growth. Residential electricity demand is growing at $1.2 \%$ per year, significantly slower than the $5 \%$ average annual growth rate over the past five years. The growing demand for energy for cooling and space heating, which will account for about $70 \%$ of the total energy consumed by the population, is mainly due to the annual increase in the average annual temperature, estimated at almost $0.1^{\circ} \mathrm{C}$ per year. Kuwait intends to build 128,000 new housing units by 2035 , all of which will meet the higher standards set out in the latest energy conservation codes and regulations. Government agencies are responsible for ensuring proper compliance with building codes [24].

In terms of industry development, renewable energy may account for the largest share of total final energy consumption (TFEC) in the construction sector. In Kuwait, energy efficiency is a key pillar, which mainly consists of modernization, refurbishment, and renovation activities, as well 
as the introduction of higher standards for household electrical appliances and the reduction of emissions from the construction of new buildings [37].

Evaluation of the efficiency of using renewable energy sources in energy-efficient buildings was carried out using technologies such as flat plate thermosiphon units, built-in collector storage, solar collectors with colored absorbers, solar collectors with booster reflectors, unglazed solar collectors, Fresnel lens for building atriums, hybrid integrated (solar-wind) systems.

It is anticipated that small solar water heaters such as flat plate thermosiphon units (FPTUs) and integral collector storage (ICS) systems may be relevant for Kuwait. In Kuwait, ICS solar systems are easier to use and less expensive than FPTU systems because of their simpler assembly design. Single families may install the ICS system in their homes as a stand-alone unit, while industrial facilities may have these systems connected to an insulated storage tank inside a building for larger applications.

Solar collectors with colored absorbers (SCCA), used for hot water supply, possess great potential in the Kuwait's solar energy sector. SCCA have many advantages over the conventional black collectors such as lower absorption and lower thermal efficiency. They also come in different colors, which allow making the façade walls and roofs of buildings more attractive to the eye. In terms of cost, increasing the collector area by $20 \%$ or so will give a similar heat output as if it was a black-absorber collector of the same type.

Solar collectors with booster reflectors (SCBR), used for hot water supply, placed between the collector rows produce about 20 to $50 \%$ more energy comparing to collectors without booster reflectors. They are suitable for horizontal roofs, which is also driving demand in Kuwait. Not only does this type of installation operates at high (spring and autumn) temperatures, it also adapts to the cooling requirements of the room, which is very important in Kuwait's climatic conditions.

Unglazed solar collectors (USC) may be used an alternative technology in hot water heating applications. Integrating open collectors with colored absorbers will make the look of the Kuwait building more interesting.

Hybrid photovoltaic systems achieve a higher efficiency of energy conversion thanks to their design (these systems consist of PV modules and water or heat extracting units). Thus, some configurations such as the PV-Trombe wall may be used as a room cooling system.

Fresnel lenses (FLS) are devices suitable for concentrating solar radiation and are lighter, have less focal length, and are less expensive than thick conventional lenses. Because Fresnel lenses separate direct from scattered solar radiation, they may be used in Kuwait buildings for lighting and interior temperature control.

Hybrid Photovoltaic-Wind Systems (HPVWS) can offer great opportunities in Kuwait's solarwind power generation. In areas where weather conditions are favorable, such as the rural regions, the combined use of PV and wind turbines gives excellent results for most of the day-night period.

The results of an analysis of the level of energy efficiency of buildings in Kuwait based on renewable sources are shown in Figure 3. The basis for determining the level of energy efficiency is the proposed model, namely the determination of the mathematical expectation of energy savings in buildings as a result of introducing renewable energy technologies. When diagnosing the level of energy savings from the use of renewable energy sources, the technical capabilities of the technologies under study, as well as prices and tariffs for energy in Kuwait for 2017-2019, were taken into account. This takes into account the average notional cost of energy savings based on reducing the use of primary fossil energy sources.

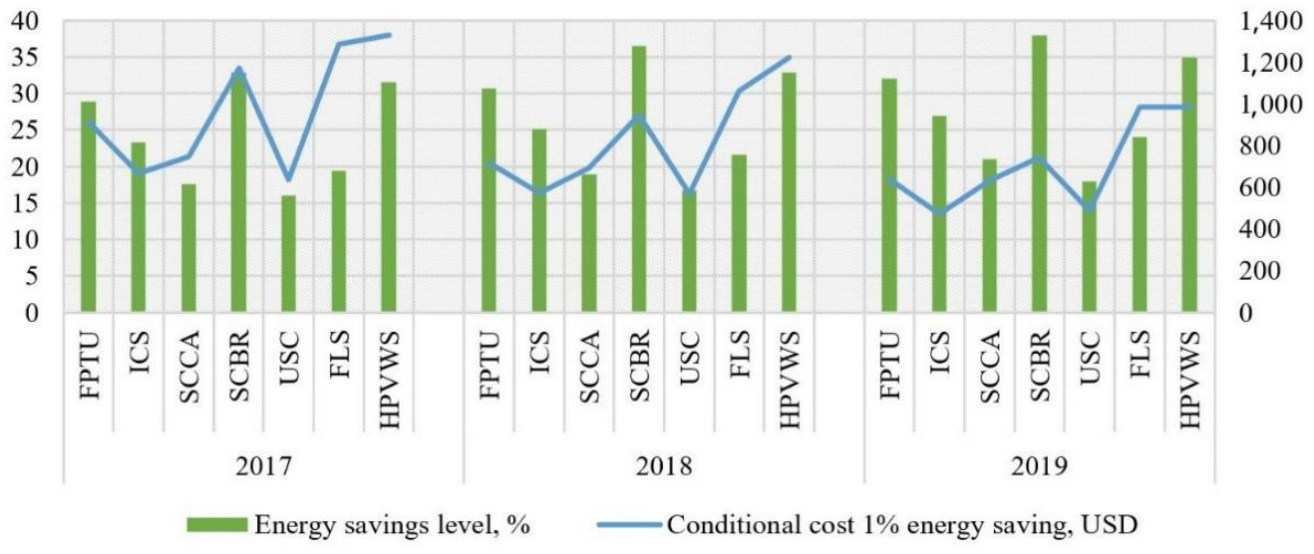

Figure 3. Energy efficiency level of renewable buildings based on renewable sources in Kuwait. Source: built by the author. 
Thus, solar energy systems such as FPTU have been the most readily available for widespread building applications in Kuwait over the past three years. Increasing energy efficiency while decreasing the notional cost of $1 \%$ of energy savings in Kuwait is typical for SCBR. The main prerequisite for this is the ability of horizontal roofs of buildings to effectively use booster reflectors to convert the incoming solar radiation. A slight decrease in the notional cost of energy savings is recorded for FLS, with the help of which lighting and temperature control in the interior of a building can be achieved. They require special maintenance and as an alternative to the building, new solar devices and hybrid systems can be used. For example, wind power systems can be seen not only as more interesting renewable energy devices for buildings in combination with solar systems, but also take into account installation and maintenance costs. At the same time, the level of cost of improving the energy efficiency of buildings decreases over the studied period.

In order to determine the effectiveness of the introduction of renewable energy technologies in buildings in Kuwait, an investment assessment was carried out (Figure 4).

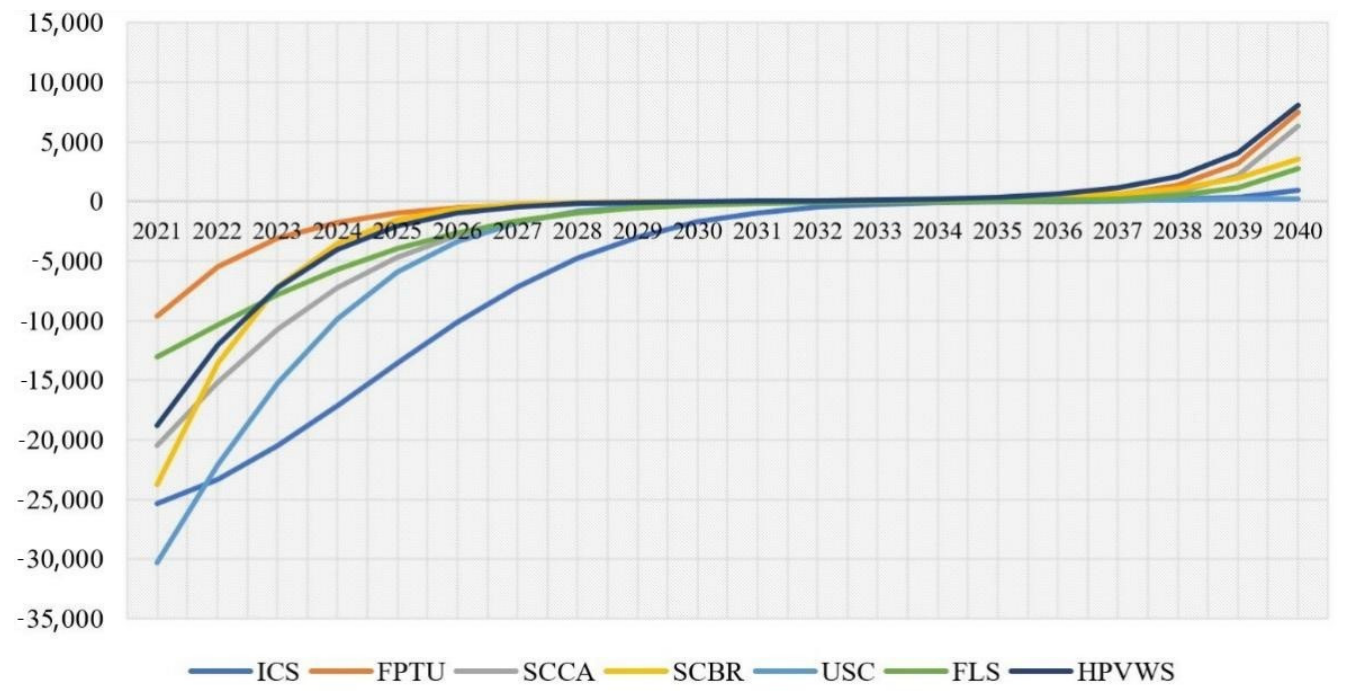

Figure 4. Investment efficiency of introducing renewable energy technologies in buildings in Kuwait based on net present value (NPV). Source: formed by the author.

In Kuwait, virtually all renewable energy technologies in buildings pay off in less than 20 years. The most beneficial, according to the modeled NPV level, are HPVWS, FPTU, and SCCA. The payback period for HPVWS is 10 years, for FPTU-12 years and SCCA-14 years. The least attractive, from an economic point of view, are USCs. Despite a fairly fast payback period (13 years), NPV for USC has the lowest rate among all the technologies studied (\$246). Although they are popular in other countries due to the expansion of design and architectural opportunities, given the climatic conditions of Kuwait, the feasibility of their implementation is low. This affects the level of demand and cost.

The efficiency of the introduction of renewable energy resources depends not only on the technologies for their use but also on the methods of storing the generated energy. This is because it is desirable to install energy storage systems in addition to renewable power energy. The main reason for this is that solar power energy is generated unevenly throughout the day. For example, solar energy is generated only during daylight hours but is consumed throughout the day. When a cloudy day comes, the total energy generated may be less than the building's daily electricity consumption. Therefore, a forecast of the effectiveness of the introduction of renewable energy technologies in buildings was carried out, taking into account investments in storage systems (Figure 5). At the same time, the peculiarities of "storing" energy for the technologies under study were taken into account. For example, for technologies designed to heat water, storage tanks are provided to store it and maintain its temperature. For on-site power generation technologies, special systems for its accumulation are required. Since these systems have technological differences, the forecast assumes that the average cost of such an installation is $60 \%$ of the cost of implementing renewable energy technologies in buildings. At the same time, the fact that the service life of such a system does not exceed 10 years was taken into account. Since the cost of energy storage systems decreases annually, one can also assume that at the end of the life of the storage system, its cost will be half of the initial. 


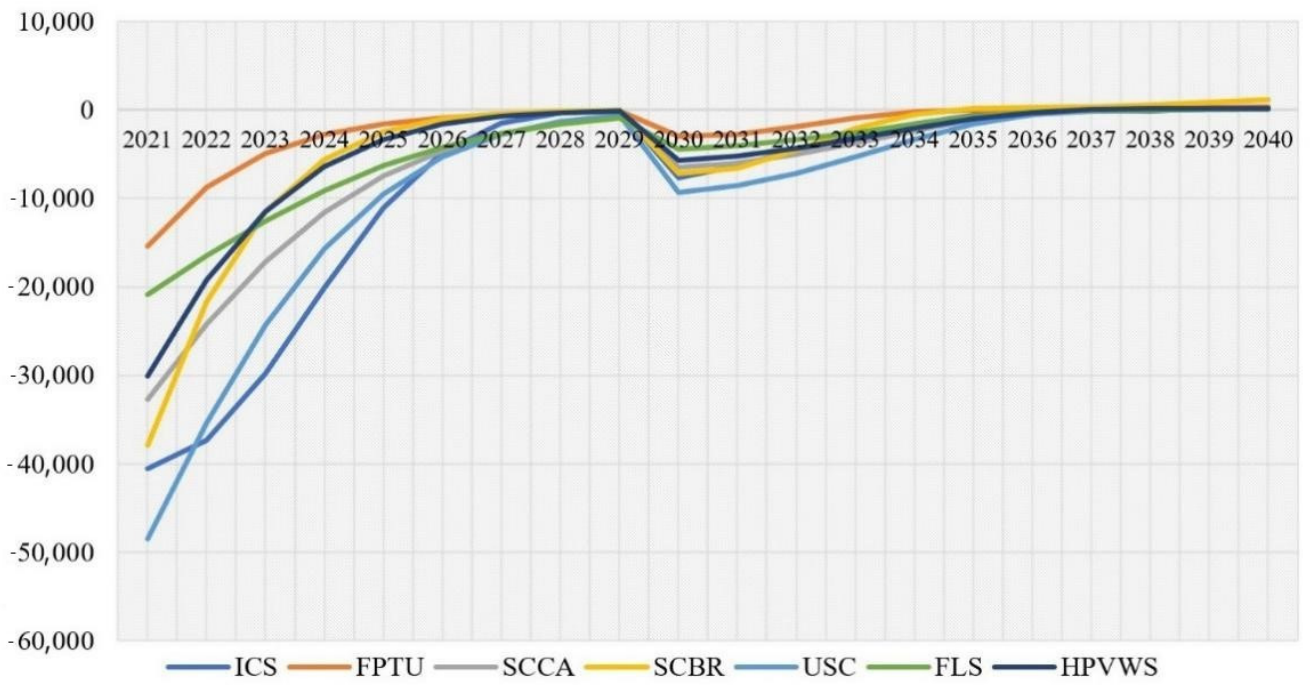

Figure 5. Implementing renewable energy technologies in Kuwait's buildings and energy storage systems on a net present value basis (NPV). Source: formed by the author.

The integrated implementation of renewable energy technologies with energy storage systems significantly affects their payback period. For example, for HPVWS, it will increase by 6 years (up to 16 years in general), for FPTU-by 3 years (up to 15 years in general), for SCCA-by 4 years (up to 16 years in general). For other technologies, the payback period is approaching 2040 (up to 20 years in general). Despite the fact that the net present value is at a very low level, it has a positive value, which confirms the feasibility of the integrated implementation of renewable energy technologies in Kuwait's buildings.

Based on the assessment of the investment efficiency of the introduction of renewable energy technologies in the buildings of Kuwait, a forecast of the level of energy saving was formed (Figure 6).

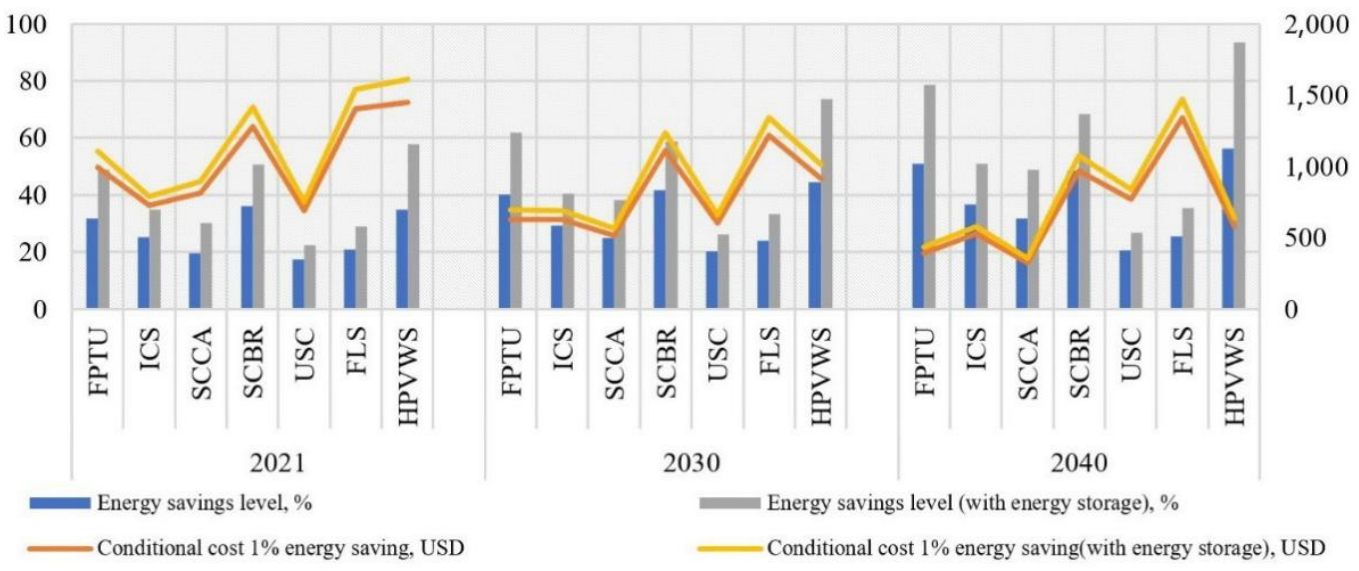

Figure 6. Forecast indicators of energy savings of buildings as a result of introducing renewable energy technologies in buildings in Kuwait. Source: formed by the author.

The highest level of energy savings is observed for technologies such as HPVWS, FPTU, and SCBR, on the basis of which energy savings can be achieved in the building until $2030-39-42 \%$, and by $2040-48-53 \%$. The use of energy storage systems increases the notional cost of $1 \%$ of energy savings, but its level can increase much more. For technologies such as HPVWS, FPTU, and SCBR, energy savings can be increased 1.5 times. Until 2040, the active introduction of HPVWS technology can provide $93 \%$ energy savings, while USC $-27 \%$. Among the studied technologies, the lowest notional cost of $1 \%$ energy saving is typical for FPTU.

With the aim of a deeper study of the implemented renewable energy technology and its storage system in buildings, a two-factor analysis of variance was carried out. Its results are shown in Table 1. The following key indicators were used: SS-Sums of Squares, df-Degrees of freedom, MS-Mean 
Squares, F-actual value of Fisher's ratio, $p$-value probability of error, Fcrit.-critical value of Fisher's ratio and Factor Influence.

Table 1. Indicators of two-factor analysis of variance for the effectiveness of renewable energy technology implementation and its storage system.

\begin{tabular}{ccccccccc}
\hline Table & $\begin{array}{c}\text { Source } \\
\text { Variation }\end{array}$ & SS & df & MS & F & $p$-Value & F Crit. & $\begin{array}{c}\text { Factor } \\
\text { Influence }\end{array}$ \\
\hline \multirow{2}{*}{ ICS } & Evtech & 875460 & 2 & 437730 & 75.85 & 0.000000002 & 3.55 & 0.87 \\
& Evst & 24991 & 2 & 12496 & 2.17 & 0.143660265 & 3.55 & 0.02 \\
FPTU & Evtech & 1538179 & 2 & 769089 & 75.73 & 0.000000002 & 3.55 & 0.85 \\
& Evst & 86063 & 2 & 43031 & 4.24 & 0.031044966 & 3.55 & 0.05 \\
SCCA & Evtech & 747924 & 2 & 373962 & 76.75 & 0.000000002 & 3.55 & 0.86 \\
& Evst & 31748 & 2 & 15874 & 3.26 & 0.022002871 & 3.55 & 0.04 \\
SCBR & Evtech & 2358598 & 2 & 1179299 & 75.66 & 0.000000002 & 3.55 & 0.84 \\
& Evst & 172364 & 2 & 86182 & 5.53 & 0.013430311 & 3.55 & 0.06 \\
USC & Evtech & 775297 & 2 & 387649 & 75.77 & 0.000000002 & 3.55 & 0.85 \\
& Evst & 37228 & 2 & 18614 & 3.64 & 0.047100000 & 3.55 & 0.04 \\
FLS & Evtech & 3441818 & 2 & 1720909 & 75.80 & 0.000000002 & 3.55 & 0.86 \\
& Evst & 140907 & 2 & 70454 & 3.10 & 0.069516960 & 3.55 & 0.04 \\
HPVWS & Evtech & 2921450 & 2 & 1460725 & 75.70 & 0.000000002 & 3.55 & 0.84 \\
& Evst & 186675 & 2 & 93337 & 4.84 & 0.020837057 & 3.55 & 0.05 \\
\hline
\end{tabular}

Source: formed by the author.

The choice of renewable energy technology has a particular impact on the level of energy savings in buildings. This is confirmed by the $p$-value $<0.05$. The degree of influence of renewable energy technology is $84-87 \%$. At the same time, the introduction of energy storage systems does not have an impact on the level of energy saving for absolutely all technologies under study (Figure 7).

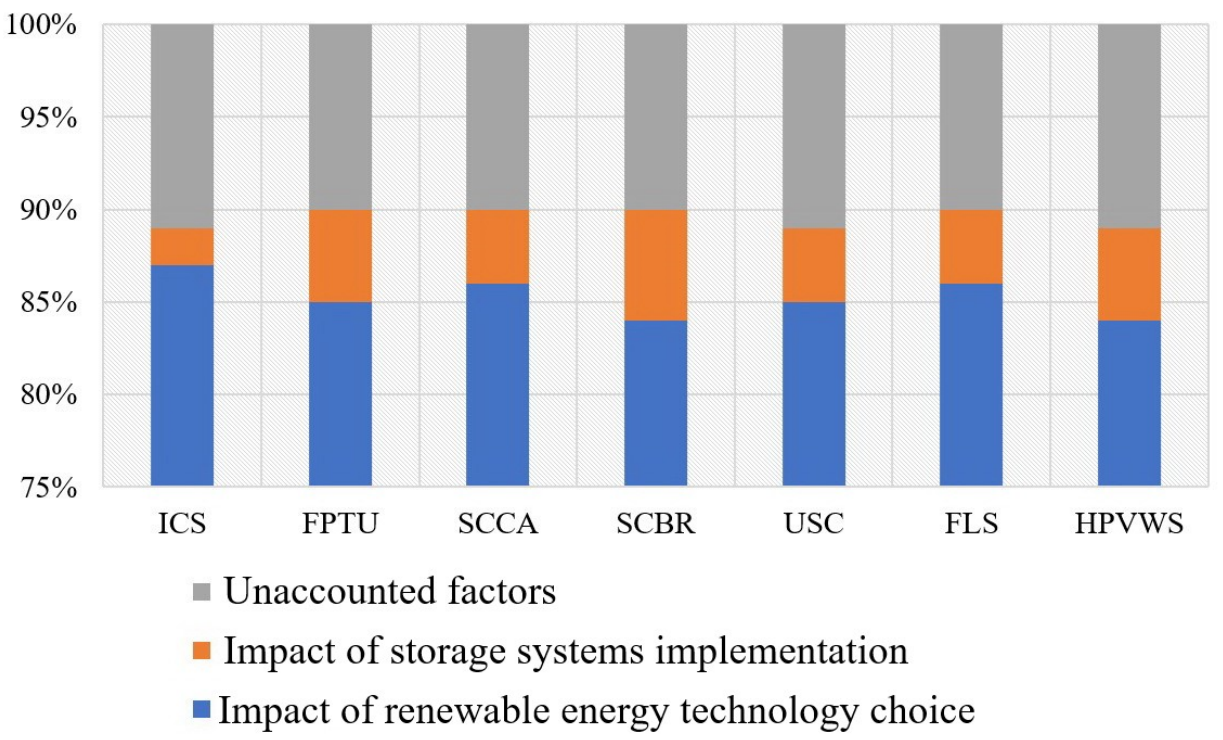

Figure 7. Influence of the choice of renewable energy technology and the implementation of energy storage systems on energy saving level. Source: formed by the author.

This can be explained by the fact that, for example, ICS and FLS are less adapted to the conversion and storage of large amounts of energy. However, in general, for five out of seven investigated renewable energy technologies, the introduction of energy storage systems has a fairly high degree of influence on the level of energy saving-about $5 \%$. Thus, this study not only confirms the stated Hypotheses $\mathrm{H} 1$ and $\mathrm{H} 2$, but at the same time also suggests that at this stage, the choice of renewable energy technology has a higher impact on the level of energy savings in Kuwait buildings than energy storage systems. It also provides an opportunity to identify the most influential renewable energy technology that has great potential in Kuwait. At the same time, among these technologies, the lowest notional cost of $1 \%$ energy saving is typical for FPTU. Thus, through the introduction of renewable energy technologies for buildings and the use of modern equipment, it is possible to significantly save energy costs. In building projects, it is advisable to use modern, innovative technologies that are able to accumulate and absorb energy, in particular, SCCA. The use of energy-saving technologies and materials as well as improving the energy efficiency of construction industry facilities can be considered as the priority areas of Kuwait's modern development in the context of its transition to sustainable energy. 


\section{Discussion}

This study not only proves the high impact of the choice of renewable energy technology, especially HPVWS, FPTU, and SCBR, and energy storage on the cost of $1 \%$ of the building's energy savings, but also allows one to determine the extent of this impact. Thus, it confirms the direct impact on the level of energy savings, which is a consequence of investment in the process of introducing renewable energy technologies in buildings in Kuwait.

The proposed model for assessing the level of energy saving provides an opportunity for an economic justification for introducing a particular technology. At the same time, a significant limitation of this study is the general assumptions of the technical characteristics of the technologies being introduced, which may differ in capacity, service life, energy storage volume, cost of assembly depending on the characteristics of the building, etc. Therefore, the results can be more accurate for a specific project or program with precise technical characteristics and implementation timeframes. At the same time, forecasting in the study was carried out for a sufficiently long-term period, for which new breakthrough technologies may appear. It is not possible to predict which ones at present, but this factor can also affect the final resulting indicators.

Improving the energy efficiency of buildings through the introduction of renewable energy technologies is essential to achieve Kuwait's sustainable development scenario. Based on the proposed methodological approach to assessing energy savings in buildings, it is recommended for this state to introduce mandatory building codes and regulations over the next decade, including hybrid technologies [38] to meet the ambitions formed today and make the introduction of renewable energy technologies in buildings a clear policy priority. However, it should be noted that high-efficiency, zero-carbon buildings are essential to realizing the ambition in the context of Kuwait's sustainable development [39]. Clear and detailed metrics need to be set to identify energy-efficient buildings with zero carbon emissions and market targets for energy efficiency in buildings need to be established to identify and guide investors' priorities. The government can serve as an example for implementing these measures, for example, based on established requirements for high-performance and energyefficient construction for new public buildings. Financial incentives should also be generated to motivate high-performance solutions for integrating renewable energy technologies with Kuwait buildings [40]. In the future, this study can be deepened towards the formation of a complex of state incentives for construction projects and environmentally friendly materials. The main premise for this is that implementing high-performance construction and renovation activities will require greater access to finance, as well as innovative business models that bring together borrowers, lenders and regulators. Kuwait can do this with policies that shape market rules to improve access to finance and reduce the risks for clean energy investments [41]. For example, these measures may include the use of tax incentives, grants, loans, auctions, and obligations [42]. The government can also work with the financial sector, banks, and investors, in particular to create a common classification scheme and a reliable evidence base for such investments [43]. Standardizing verification procedures to reduce uncertainties associated with energy savings estimates will help investors understand the benefits of scaling up investments and their repeatability, making investments more attractive.

In Kuwait, existing buildings likely represent a significant proportion of buildings that need to be upgraded. Therefore, large-scale refurbishment of buildings should be a key political priority for the state in the coming decade [44]. In the future, this study can be aimed at assessing the effectiveness of building renovation in the context of renewable energy technologies [45]. At the same time, it is necessary to overcome a significant limitation, which consists in compiling a comprehensive and reliable base of factual technical and economic data, as well as experimental programs with the help of which it will be possible to demonstrate effective results as well as their deviations. Further research can review the prospects for the creation of various classes, such as commercial, industrial, and household. Since the above classes have different purposes, it is possible to integrate different technologies in the context of the best practice.

This study's limitation is the fact that the construction of a building using renewable technologies involves a complex integrated solution. Therefore, the technologies under study can be complementary in the context of meeting different energy needs. However, it is not possible to assess their synergy, because each building structure has its own purposes and specific features of operation.

The projections of building energy savings from the introduction of renewable energy technologies in Kuwait will ultimately need to be reinforced with increased participation and coordinated action among the various stakeholders and government agencies involved in the energy scenario and design process. The study can help develop long-term strategies that take into account both energy and climate aspects in Kuwait in the context of the introduction of renewable energy technologies in buildings. The results of this study can be useful to those responsible for the formation of long-term 
strategies, projects, and programs that take into account both energy and climate aspects in Kuwait in the context of the introduction of renewable energy technologies in buildings.

\section{Conclusions}

The results obtained in this study allow drawing comprehensive conclusions about the features of the used renewable energy technologies for buildings and their long-term implementation effectiveness for Kuwait.

1. The use of renewable energy sources has increased significantly in Kuwait over the past three years. Energy efficiency is a key element, which mainly consists of implementing modernization, refurbishment, and renovation measures, as well as introducing higher standards for household electrical appliances and reducing emissions from new buildings. Although the 2017 Code for Government and Commercial Buildings in Kuwait has established minimum regulatory requirements, improving energy efficiency in the construction sector still requires clear long-term government policies combined with comprehensive strategies based on adequate capacity to implement them.

2. The investment efficiency of the introduction of renewable energy technologies in buildings in Kuwait on a net present value basis confirms that virtually all renewable energy technologies in buildings pay off in up to 20 years. The most profitable from an economic point of view are hybrid photovoltaic-wind systems, flat plate thermosiphon units, and solar collectors with colored absorbers. Moreover, these technologies have the fastest payback period. Unglazed solar collectors are the least profitable. Although this technology has a fairly fast payback period, unglazed solar collectors have the lowest NPV. Despite their popularity in other countries, taking into account the possibilities of expanding design and architectural possibilities, but in the climatic conditions of Kuwait, they do not have reasonable feasibility of implementation.

3. The installation of energy storage systems plays a special role in the implementation of renewable energy technologies in buildings. Despite the fact that this requires additional investment and increases the payback period of the technology in the complex, the addition of storage systems can significantly increase the level of energy savings in buildings. In particular, for technologies such as HPVWS, FPTU, and SCBR, energy savings using energy storage systems can significantly increase compared to their implementation only for energy conversion. This should be taken into account when formulating government programs to increase the level of energy saving of buildings in Kuwait since this aspect contributes to a higher level of self-sufficiency of energy for the population or government buildings.

4. Based on the predicted energy savings of buildings resulting from the introduction of renewable energy technologies in Kuwait's buildings, the highest level of energy savings for technologies such as hybrid photovoltaic-wind systems, flat plate thermosiphon units, and solar booster collectors has been determined. Based on the introduction of these technologies in a building, energy savings can be achieved at the level of $39-42 \%$ until 2030 and $48-53 \%$ until 2040 . ANOVA has confirmed the high impact of renewable energy technology on the level of energy savings in buildings, the degree of which is $84-87 \%$. At the same time, technologies have been identified in which the introduction of energy storage systems does not have a particular effect on the level of energy saving. These include ICS and FLS. Taking into account the fact that most of the studied renewable energy technologies with energy storage systems have a fairly high degree of influence on the level of energy saving, this study confirms that the choice of renewable energy technology is more relevant for increasing energy saving in buildings in Kuwait at the present stage of its development. At the same time, energy storage systems can be an effective addition to the development of complex projects and energy-saving programs for buildings in Kuwait.

5. The proposed model for assessing the level of energy saving provides an opportunity for economic justification of introducing renewable energy technology in buildings. Based on the forecast, one can state the expected efficiency of investment projects in Kuwait based on HPVWS, FPTU, SCBR technologies, which are designed for a period of up to 20 years. At the same time, the investment plan in Kuwait cannot be focused on the short-term perspective, since at the moment none of the technologies under study involves obtaining a positive NPV for a period of up to 10 years. When assessing the required investment, it should be noted that adding storage to renewable energy technologies in buildings on average increases the notional cost of $1 \%$ energy savings by $67 \%$. At the same time, its level is on average 1.5 times higher than without the introduction of storage systems.

By introducing renewable energy technologies for buildings and using modern equipment in Kuwait, significant energy savings are possible, reducing the negative impact on the environment, improving comfortable conditions and living standards for the population, as well as increasing the level of sustainable development of the country as a whole. The use of renewable technologies 
to improve the energy efficiency of construction facilities in Kuwait is a priority area of modern development in the context of renewable energy and adaptation to the country's energy transition as a whole.

Funding: This research received no external funding.

Institutional Review Board Statement: Not applicable.

Informed Consent Statement: Not applicable.

Data Availability Statement: All data will be available on request.

Conflicts of Interest: The author declares no conflict of interest.

\section{References}

1. World Economic Forum. The Net-Zero Challenge: Global Climate Action at a Crossroads. 2019. Available online: http: //www3.weforum.org/docs/WEF_The_Net_Zero_Challenge_Part1.pdf (accessed on 12 March 2021).

2. European Commission. Renewable Energy, Moving towards a Low Carbon Economy; European Commission: Brussels, Belgium, 2020; Available online: https:/ / ec.europa.eu/energy/en/topics/renewable-energy (accessed on 12 March 2021).

3. U.S. Energy Information Administration. Renewable Energy US EIA. 2018. Available online: https://www.eia.gov/ energyexplained/?page=renewable_home (accessed on 12 March 2021).

4. Stokes, L.C.; Breetz, H.L. Politics in the US energy transition: Case studies of solar, wind, biofuels and electric vehicles policy. Energy Policy 2018, 113, 76-86. [CrossRef]

5. International Energy Agency. Market Report Series: Renewables 2018 OECD/IEA; International Energy Agency: Paris, France, 2018; Available online: https:/ / www.iea.org/renewables2018/ (accessed on 12 March 2021).

6. IRENA. Renewable Energy Prospects for the Russian Federation; IRENA: Abu Dhabi, United Arab Emirates, 2017; Available online: https:/ / www.irena.org/-/media/Files/IRENA/Agency/Publication/2017/Apr/IRENA_REmap_Russia_paper_2017 .pdf (accessed on 12 March 2021).

7. Steensma, G.; Román, R.; Marshall, C.; Bermejo, J.; Iyer, K.; Al-Hajraf, S.; Al-Qattan, A. Shagaya renewable energy park project. In AIP Conference Proceedings; AIP Publishing LLC: Melville, NY, USA, 2019; Volume 2126, p. 040003.

8. Pérez, M.D.L.E.M.; Scholten, D.; Stegen, K.S. The multi-speed energy transition in Europe: Opportunities and challenges for EU energy security. Energy Strategy Rev. 2019, 26, 100415. [CrossRef]

9. D'Agostino, D.; Mazzarella, L. What is a Nearly zero energy building? Overview, implementation and comparison of definitions. J. Build. Eng. 2019, 21, 200-212. [CrossRef]

10. Prokazov, I.; Gorbanyov, V.; Samusenkov, V.; Razinkina, I.; Chłą, M. Assessing the flexibility of renewable energy multinational corporations. Energies 2021, 14, 3865. [CrossRef]

11. University of Southampton. Climate Change World Weather File Generator for World-Wide Weather Data-CCWorldWeatherGen. 2016. Available online: http:/ / www.energy.soton.ac.uk/ccworldweathergen/ (accessed on 6 July 2021).

12. Rey-Hernández, J.M.; Yousif, C.; Gatt, D.; Velasco-Gómez, E.; San José-Alonso, J.; Rey-Martínez, F.J. Modelling the long-term effect of climate change on a zero energy and carbon dioxide building through energy efficiency and renewables. Energy Build. 2018, 174, 85-96. [CrossRef]

13. N-Lex. Directive (EU) 2018/844 of the European Parliament and of the Council of 30 May 2018 Amending Directive 2010/31/EU on the Energy Performance of Buildings and Directive 2012/27/EU on Energy Efficiency. 2018. Available online: http:/ / data. europa.eu/eli/dir/2018/844/oj (accessed on 6 July 2021).

14. Wang, Y.; Du, J.; Kuckelkorn, J.M.; Kirschbaum, A.; Gu, X.; Li, D. Identifying the feasibility of establishing a passive house school in central Europe: An energy performance and carbon emissions monitoring study in Germany. Renew. Sustain. Energy Rev. 2019, 113, 109256. [CrossRef]

15. da Guarda, E.L.A.; Domingos, R.M.A.; Jorge, S.H.M.; Durante, L.C.; Sanches, J.C.M.; Leão, M.; Callejas, I.J.A. The influence of climate change on renewable energy systems designed to achieve zero energy buildings in the present: A case study in the Brazilian Savannah. Sustain. Cities Soc. 2020, 52, 101843. [CrossRef]

16. Shukla, A.K.; Sudhakar, K.; Baredar, P.; Mamat, R. BIPV based sustainable building in South Asian countries. Sol. Energy 2018, 170, 1162-1170. [CrossRef]

17. Yang, X.; Zhang, S.; Xu, W. Impact of zero energy buildings on medium-to-long term building energy consumption in China. Energy Policy 2019, 129, 574-586. [CrossRef]

18. Tsindeliani, I.; Matyanova, E.; Razgildeev, A.; Vasilyeva, E.; Dudnik, D.; Mikhailova, A. Tax Optimization in the modern tax system under the influence of digitalization: Russian case study. Eur. J. Comp. Law Gov. 2021, 1, 1-24. [CrossRef]

19. Kim, J.T.; Yu, C.W.F. Sustainable development and requirements for energy efficiency in buildings-the Korean perspectives. Indoor Built Environ. 2018, 27, 734-751. [CrossRef]

20. Pobedinsky, V.; Shestak, V. Improving Environmental Legislation in Central Asia. Env. Policy Law 2020, 50, 69-79. [CrossRef]

21. Park, J.; Kim, T.; Lee, C.S. Development of thermal comfort-based controller and potential reduction of the cooling energy consumption of a residential building in Kuwait. Energies 2019, 12, 3348. [CrossRef] 
22. El, H. The impact of oil prices on stocks markets: New evidence during and after the Arab spring in gulf cooperation council economies. Int. J. Energy Econ. Policy 2019, 9, 214-223.

23. Shehabi, M. Diversification effects of energy subsidy reform in oil exporters: Illustrations from Kuwait. Energy Policy 2020, 138, 110966. [CrossRef]

24. Kuwait Institute for Scientific Research. Kuwait Energy Outlook. 2019. Available online: https://www.arabstates.undp.org/ content/rbas/en/home/library/Sustainable_development/kuwait-energy--outlook.html (accessed on 12 March 2021).

25. Soares, N.; Reinhart, C.F.; Hajiah, A. Simulation-based analysis of the use of PCM-wallboards to reduce cooling energy demand and peak-loads in low-rise residential heavyweight buildings in Kuwait. In Building Simulation; Tsinghua University Press: Beijing, China, 2017; Volume 10, pp. 481-495.

26. Salahuddin, M.; Alam, K.; Ozturk, I.; Sohag, K. The effects of electricity consumption, economic growth, financial development and foreign direct investment on CO2 emissions in Kuwait. Renew. Sustain. Energy Rev. 2018, 81, 2002-2010. [CrossRef]

27. Rodrigues, E.; Soares, N.; Fernandes, M.S.; Gaspar, A.R.; Gomes, Á.; Costa, J.J. An integrated energy performance-driven generative design methodology to foster modular lightweight steel framed dwellings in hot climates. Energy Sustain. Dev. 2018, 44, 21-36. [CrossRef]

28. Chel, A.; Kaushik, G. Renewable energy technologies for sustainable development of energy efficient building. Alex. Eng. J. 2018, 57, 655-669. [CrossRef]

29. Lu, M.; Lai, J.H. Building energy: A review on consumptions, policies, rating schemes and standards. Energy Procedia 2019, 158, 3633-3638. [CrossRef]

30. Sedaghat, A.; Alkhatib, F.; Oloomi, S.A.A.; Sabri, F.; Salem, H.; Sabati, M.; Negahi, A. Experimental study on the performance of solar window films in office buildings in Kuwait. J. Nanopart. Res. 2020, 22, 85. [CrossRef]

31. Alsayegh, O.; Saker, N.; Alqattan, A. Integrating sustainable energy strategy with the second development plan of Kuwait. Renew. Sustain. Energy Rev. 2018, 82, 3430-3440. [CrossRef]

32. Alajmi, T.; Phelan, P. Modeling and forecasting end-use energy consumption for residential buildings in Kuwait using a bottom-up approach. Energies 2020, 13, 1981. [CrossRef]

33. Sztubecka, M.; Skiba, M.; Mrówczyńska, M.; Bazan-Krzywoszańska, A. An innovative decision support system to improve the energy efficiency of buildings in urban areas. Remote Sens. 2020, 12, 259. [CrossRef]

34. Delgado, D.; Carvalho, M.; Junior, L.M.C.; Abrahão, R.; Chacartegui, R. Photovoltaic solar energy in the economic optimisation of energy supply and conversion. IET Renew. Power Gen. 2018, 12, 1263-1268. [CrossRef]

35. International Energy Agency. World Energy Balances 2019-Kuwait. 2020. Available online: https://www.iea.org/countries/ kuwait (accessed on 12 March 2021).

36. International Renewable Energy Agency. Renewable Power Capacity in Kuwait. 2020. Available online: http:/ / resourceirena. irena.org/gateway/ countrySearch/? countryCode=KWT (accessed on 12 March 2021).

37. Bayramov, S.; Prokazov, I.; Kondrashev, S.; Kowalik, J. Household electricity generation as a way of energy independence of states-Social context of energy management. Energies 2021, 14, 3407. [CrossRef]

38. Oliveros-Cano, L.; Salgado-Meza, J.; Robles-Algarín, C. Technical-economic-environmental analysis for the implementation of hybrid energy systems. Int. J. Energy Econ. Policy 2020, 10, 57-64. [CrossRef]

39. Ismael, D.; Shealy, T. Industry perceptions of sustainable design and construction practices in Kuwait. J. Green Build. 2019, 14, 169-193. [CrossRef]

40. Munguia, N.; Esquer, J.; Guzman, H.; Herrera, J.; Gutierrez-Ruelas, J.; Velazquez, L. Energy efficiency in public buildings: A step toward the UN 2030 Agenda for sustainable development. Sustainability 2020, 12, 1212. [CrossRef]

41. Anser, M.K.; Yousaf, Z.; Zaman, K.; Nassani, A.A.; Alotaibi, S.M.; Jambari, H.; Kabbani, A. Determination of resource curse hypothesis in mediation of financial development and clean energy sources: Go-for-green resource policies. Resour. Policy 2020, 66, 101640. [CrossRef]

42. Gelan, A.U. Kuwait's energy subsidy reduction: Examining economic and CO2 emission effects with or without compensation. Energy Econ. 2018, 71, 186-200. [CrossRef]

43. Ismael, D.; Shealy, T. Sustainable construction risk perceptions in the Kuwaiti construction industry. Sustainability 2018, 10, 1854. [CrossRef]

44. Chen, S.; Zhang, G.; Xia, X.; Setunge, S.; Shi, L. A review of internal and external influencing factors on energy efficiency design of buildings. Energy Build. 2020, 216, 109944. [CrossRef]

45. Campisi, D.; Gitto, S.; Morea, D. An evaluation of energy and economic efficiency in residential buildings sector: A multi-criteria analisys on an Italian case study. Int. J. Energy Econ. Policy 2018, 8, 185-196. 